\title{
Selective Crystallization of SAPO-5 and SAPO-34 Molecular Sieves in Alkaline Condition: Effect of Heating Method
}

\author{
Ji Woong Yoon, ${ }^{\text {a,b }}$ Sung Hwa Jhung, ${ }^{\text {a }}$ Young Ho Kim, ${ }^{\mathrm{b}}$ Sang-Eon Park,,${ }^{\mathrm{c} *}$ and Jong-San Chang, \\ ${ }^{a}$ Research Center for Nanocatalysts, Korea Research Institute of Chemical Technology, P.O. Box, 107, \\ Yusung, Daejeon 305-600, Korea. *E-mail: jschang@krict.re.kr \\ ${ }^{b}$ Department of Fine Chemicals Engineering \& Chemistry, Chungnam National University, Daejeon 305-764, Korea \\ ${ }^{c}$ Department of Chemistry, Inha University, Incheon 402-751, Korea
}

Received October 28, 2004

\begin{abstract}
Crystallization of SAPO-5 and SAPO-34 molecular sieves with microwave and conventional electric heating of the same gel has been investigated in an alkaline condition using N,N,N',N'-tetraethylethylenediamine as a template molecule. SAPO-5 structure can be selectively prepared with microwave heating because of the fast crystallization of the technique. On the other hand, SAPO-34 is the sole product with usual conventional electric heating because SAPO-5 can be gradually transformed into SAPO-34 structure with an increase in crystallization time. This phase selectivity is probably because of the relative stability of the two phases at the reaction conditions (kinetic effect). Crystallization with microwave heating can be suggested as a phase selective synthesis method for relatively unstable materials because of fast crystallization.
\end{abstract}

Key Words : SAPO-5, SAPO-34, Phase selectivity, Microwave heating, N,N,N',N'-Tetraethylethylenediamine

\section{Introduction}

Porous materials including zeolites and aluminophosphate molecular sieves (AlPO) ${ }^{1}$ are widely used in catalysis and separation, and are being developed for new applications. ${ }^{2}$ Therefore, the phase selective crystallization of pure aluminophosphate type microporous materials is very important for applications and characterization.

Up to now microporous materials have been synthesized mainly by conventional electric heating using an autoclave. Since the pioneering works to use microwave technique in the synthesis of porous materials, ${ }^{3-5}$ it has been understood that synthesis of zeolites and AlPO by microwave heating has many advantages such as fast crystallization, ${ }^{3-6}$ increased phase purity, ${ }^{7}$ narrow particle size distribution ${ }^{8,9}$ and facile morphology control. ${ }^{10,11}$ The synthesis of an inorganic material by using microwave heating technique is very efficient to analyze the effect of reaction conditions ${ }^{12}$ because of the fast crystallization of the technique.

Phase selectivity by using microwave heating, however, is not well known. By using microwave heating, preferential formation of zeolite $\mathrm{NaY}$ over zeolite $\mathrm{P}$ has been reported. ${ }^{7}$ Similarly, we have reported that SAPO-5 and VAPO-5 rather than SAPO-34 and VAPO-34 can be synthesized preferentially by microwave heating. ${ }^{13,14}$ On the contrary, CoAPO34 and CoAPO-5 can be obtained by the crystallization using microwave heating and conventional electric heating, respectively, because the CoAPO-5 is more stable than CoAPO-34. ${ }^{14}$ The selective crystallization of NaY, SAPO-5, VAPO-5 and CoAPO-34 has been explained with the relative stabilities (kinetic effect) of microporous materials such as NaY, P, MeAPO-5 and MeAPO-34.,13,14

AFI type molecular sieves (AFI) ${ }^{15}$ such as AlPO-5 and
CoAPO-5 with one-dimensional channel of $0.73 \mathrm{~nm}$ have been one of the best known AlPO type molecular sieves. CHA type molecular sieves $(\mathrm{CHA})^{15}$ such as SAPO-34 and CoAPO-34 with small channel of $0.38 \mathrm{~nm}$ have been used as catalysts in the petrochemical industry such as the 'methanol to olefin' (MTO) process. ${ }^{16,17}$ The AFI and CHA molecular sieves have hexagonal and trigonal structures, respectively. ${ }^{15}$

The AFI has been usually synthesized only in acidic conditions; however, SAPO-5 and VAPO-5 can be selectively crystallized in an alkaline condition in the presence of triethylamine (TEA) by using microwave heating technique. ${ }^{13,14,18}$ The synthesis of a molecular sieve in a wide range of $\mathrm{pH}$ is very important to understand the synthesis mechanism and to find an efficient way to prepare the material. So far, the synthesis of AFI from an alkaline gel has not been reported excluding our results on the SAPO-5 and VAPO-5 using TEA. ${ }^{13,14,18}$

Molecular sieves including zeolites and AIPO have been usually prepared in the presence of suitable templates. The relationship between a template and the structure that obtained from the template (structure-template specificity) depends greatly on the type of molecular sieves. AFI and CHA are some of the structures to form readily with many different templates (more than 85 and 30 templates, respectively). ${ }^{19}$ However, the utilization of N,N,N',N'-tetraethylethylenediamine (TEEDA) for the synthesis of AFI and CHA is not well known. ${ }^{13,20}$

Herein, we report the phase selectivity or competitive crystallization of SAPO-5 and SAPO-34 from an alkaline gel containing TEEDA as a template using microwave and conventional electric heating. The synthesis of SAPO-5 from an alkaline gel containing TEEDA as a template is also discussed. 


\section{Experimental Section}

SAPO-5 and SAPO-34 molecular sieves were synthesized hydrothermally using pseudoboehmite (Catapal A, Vista), phosphoric acid (85 wt.\%, Aldrich), N,N,N',N'-tetraethylethylenediamine (98\%, Aldrich) and deionized water to follow the method reported earlier. ${ }^{10-14}$ Silica sol (Ludox HS40, 40 wt.\%, Aldrich) was used as the silica sources. Pseudoboehmite was added to the diluted phosphoric acid solution, and stirred until a white uniform gel was obtained. The template (TEEDA) and silica sol were added successively to the gel, which was stirred to an uniform reaction mixture. The typical reactant composition for the synthesis was $1.0 \mathrm{Al}_{2} \mathrm{O}_{3}: 1.0 \mathrm{P}_{2} \mathrm{O}_{5}: 0.333 \mathrm{SiO}_{2}: 3$.0TEEDA : $50 \mathrm{H}_{2} \mathrm{O}(\mathrm{pH}=9.0)$. The composition of $\mathrm{SiO}_{2}$ was adjusted to have the concentration of approximately $2 \mathrm{Si} /$ unit cell $(24 \mathrm{~T}$ atoms). The reaction conditions for the typical cases are summarized in Table 1.

The gel ( $40 \mathrm{~g})$ was loaded in a $100 \mathrm{~mL}$ Teflon autoclave, which was sealed and placed in a microwave oven (Mars-5, CEM, maximum power of $1200 \mathrm{~W}$ ). The autoclave was heated to the reaction temperature of $200{ }^{\circ} \mathrm{C}$ and kept for a predetermined time. The reaction temperature was controlled using EST-300 Plus system (Electronic SensorTemperature) that monitored and controlled temperature conditions inside sample vessels. In this system, a microwave transparent fiberoptic temperature probe was inserted into a thermowell of a sample vessel. The temperature sensor was a phosphor located at the tip of the probe. The decay rate of fluorescent light emitted from the phosphor is temperature dependent, allowing a precise determination of temperature. For safety, the temperature of the reaction vessel in the microwave oven was measured using an optional TempGuard ${ }^{\mathrm{TM}}$ system. An infrared lens and sensor were located in the microwave oven and the temperature of each vessel was measured as the vessels rotated over the sensor. If the temperature in any vessel was higher than the maximum allowable temperature, the TempGuard ${ }^{\mathrm{TM}}$ stopped microwave generation.
For conventional electric crystallization, the gel was loaded in a Teflon lined autoclave and put in a preheated electric oven (temperature was same as that of microwave oven) for a fixed time without agitation. After the reaction, the autoclave was cooled to room temperature, and the solid product was recovered by centrifugation and dried overnight at $105^{\circ} \mathrm{C}$. The molecular sieves were calcined at $550^{\circ} \mathrm{C}$ in an electric furnace to remove template molecules. No extra separation procedure was conducted to remove impurities or amorphous gel.

The phase of the samples was determined using an X-ray diffractometer (Rigaku, D/MAX IIIB, $\mathrm{CuK}_{\mathfrak{a}}$ radiation) and the surface area was measured with a BET system (Micromeritics, ASAP2400) at $-196{ }^{\circ} \mathrm{C}$ after evacuation at $300^{\circ} \mathrm{C}$. The chemical composition (Al, P, Si) was analyzed using an energy dispersive X-ray spectrometer (Philips, XL30S FEG). The yield of the solid product was calculated by comparing the amount of recovered solid with the total weight of $\mathrm{TO}_{4}$ (in the gel) such as $\mathrm{Al}_{2} \mathrm{O}_{3}, \mathrm{P}_{2} \mathrm{O}_{5}$ and $\mathrm{SiO}_{2}$ and by evaluating the relative XRD intensity ( $\left(\begin{array}{lll}1 & 0 & 0\end{array}\right)$ planes of SAPO-5 and SAPO-34). The contribution of the template and water was corrected with a weight loss at $700{ }^{\circ} \mathrm{C}$, determined with a TGA system (Du Pont 9900).

\section{Results}

Figure 1 shows the XRD patterns of SAPO molecular sieves synthesized from crystallization of an alkaline gel containing TEEDA as a template in various conditions. The XRD patterns of Figures 1(a) and (b) correspond to the pattern of known AFI structure ${ }^{21}$ and Figure 1(d) correspond to the XRD pattern of CHA structure. ${ }^{22}$ The XRD patterns of Figure 1(a) and 1(b) are nearly identical to show little change of the structure with the crystallization time (0.5-2 h). Figure 1(c) shows the pattern of mixed phases of AFI and CHA, which represents the mixtures containing SAPO-5 and SAPO-34 are obtained in the early stage $(12 \mathrm{~h})$ of the conventional heating and the SAPO-34 is the sole product after $48 \mathrm{~h}$ of reaction. The SAPO molecular sieves obtained

Table 1. The preparation conditions and results for the synthesis of the SAPO molecular sieves ${ }^{a}$

\begin{tabular}{|c|c|c|c|c|c|c|}
\hline $\begin{array}{l}\text { Sample } \\
\text { Number }\end{array}$ & $\begin{array}{l}\text { Heating } \\
\text { Method }^{b}\end{array}$ & $\begin{array}{l}\text { Heating } \\
\text { Time (h) }\end{array}$ & Obtained Phase $^{c}$ & $\mathrm{~S}_{\mathrm{BET}}^{d}$ & $\begin{array}{l}\text { Crystallization } \\
\text { yield }(\%)\end{array}$ & $\begin{array}{c}\mathrm{Si} /(\mathrm{Si}+\mathrm{Al}+\mathrm{P}) \\
(\text { atom \%) }\end{array}$ \\
\hline $\mathrm{A}$ & MW & 0.5 & SAPO-5 (100) & 300 & 25.1 & 8.1 \\
\hline B & MW & 1 & SAPO-5 (100) & 300 & 65.6 & 7.4 \\
\hline $\mathrm{C}$ & MW & 2 & SAPO-5 (100) & 310 & 79.0 & 8.5 \\
\hline \multirow{2}{*}{$\mathrm{D}^{e}$} & \multirow{2}{*}{$\mathrm{CE}$} & \multirow{2}{*}{12} & SAPO-5 (78.0) & \multirow{2}{*}{$370^{f}$} & 28.0 & \multirow{2}{*}{$8.6^{f}$} \\
\hline & & & SAPO-34 (22.0) & & 7.9 & \\
\hline \multirow{2}{*}{$\mathrm{E}^{e}$} & \multirow{2}{*}{$\mathrm{CE}$} & \multirow{2}{*}{24} & SAPO-5 (75.8) & \multirow{2}{*}{$390^{f}$} & 63.6 & \multirow{2}{*}{$7.6^{f}$} \\
\hline & & & SAPO-34 (24.2) & & 20.3 & \\
\hline $\mathrm{F}$ & $\mathrm{CE}$ & 48 & SAPO-34 (100) & 650 & 79.0 & 8.6 \\
\hline
\end{tabular}

${ }^{a}$ Composition of reaction mixtures was $\mathrm{Al}_{2} \mathrm{O}_{3}: 1.0 \mathrm{P}_{2} \mathrm{O}_{5}: 0.33 \mathrm{SiO}_{2}: 3.0 \mathrm{TEEDA}: 50 \mathrm{H}_{2} \mathrm{O}\left(\mathrm{pH}=9.0\right.$ ), Reaction temperature was $200{ }^{\circ} \mathrm{C} .{ }^{b} \mathrm{MW}:$ microwave heating, CE: conventional electric heating. ${ }^{c}$ The figures in parentheses are the relative content of the phase (SAPO-5 or SAPO-34). ${ }^{d} \mathrm{BET}$ surface area $\left(\mathrm{m}^{2} / \mathrm{g}\right) .{ }^{e}$ Mixture of SAPO-5 and SAPO-34 was obtained. ${ }^{f}$ Determined for the mixture of SAPO-5 and SAPO-34. 


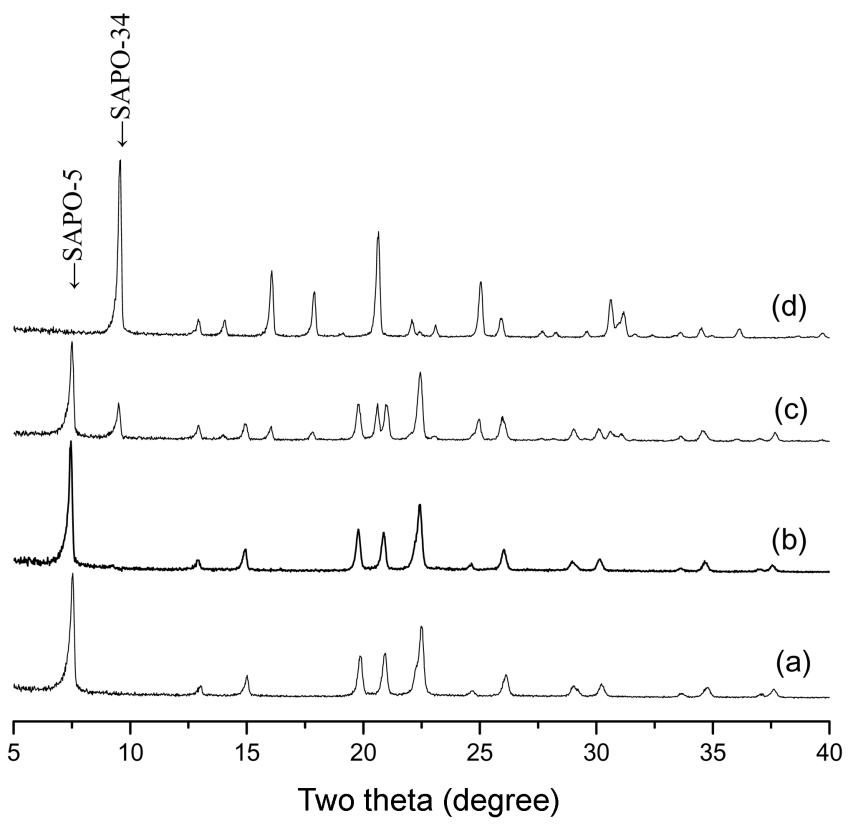

Figure 1. XRD patterns of SAPO molecular sieves synthesized from same alkaline gel containing TEEDA with microwave and conventional electric heating ((a): microwave heating for $0.5 \mathrm{~h}$, sample no. A of Table 1; (b): microwave heating for $2 \mathrm{~h}$, sample no. $\mathrm{C}$ of Table 1; (c): conventional electric heating for $12 \mathrm{~h}$, sample no. $\mathrm{D}$ of Table 1; (d) conventional electric heating for $48 \mathrm{~h}$, sample no. D of Table 1).

by microwave heating show typical hexagonal prism as shown by the SEM images (Figs. 2(a) and (b)), whereas, the SEM image of Figure 2(c) shows a mixture of hexagonal prism and cubic or rhombohedral morphology. The crystals obtained from conventional heating for $48 \mathrm{~h}$ show large cubic or rhombohedral morphology (Fig. 2(d)).

The detailed synthesis results including crystallization yield and BET surface area are summerized in Table 1. As shown in Figure 1 and Table 1, SAPO-5 is obtained by microwave heating, whereas, SAPO-34 is produced by the conventional electric heating at the later stage of the reaction. All the SAPO molecular sieves are microporous, having BET surface area of $300-650 \mathrm{~m}^{2} / \mathrm{g}$ depending on the structure and composition. Considering the BET surface area of SAPO-5 and SAPO-34 and the relative composition of the products (Table 1), the produced SAPO molecular sieves seem free from amorphous or non-porous materials in high content. The $\mathrm{Si} /(\mathrm{Si}+\mathrm{Al}+\mathrm{P})$ ratios of the product are from 7.4-8.6, not showing any dependence on the reaction conditions. Moreover, the obtained ratios are similar to the ratio of the reactant mixture of 7.62 atom $\%$. These results described above demonstrate that SAPO-5 and/or SAPO-34 may be produced in highly pure state from an alkaline gel.

The crystallization yields calculated from the obtained weight and XRD intensity are also shown in Table 1. The total yield (SAPO-5 and SAPO-34) increases with the crystallization time for both crystallization methods. In the case of conventional heating, SAPO-34 content increased with the crystallization time, whereas the yield of SAPO-5 increased with time up to $24 \mathrm{~h}$ and disappears after $48 \mathrm{~h}$ of reaction. The change of crystallization yield with reaction time and heating method is compared in Figure 3. As shown in Figure 3(b), the SAPO-5 transforms into SAPO-34 with the increase of crystallization time for the conventional
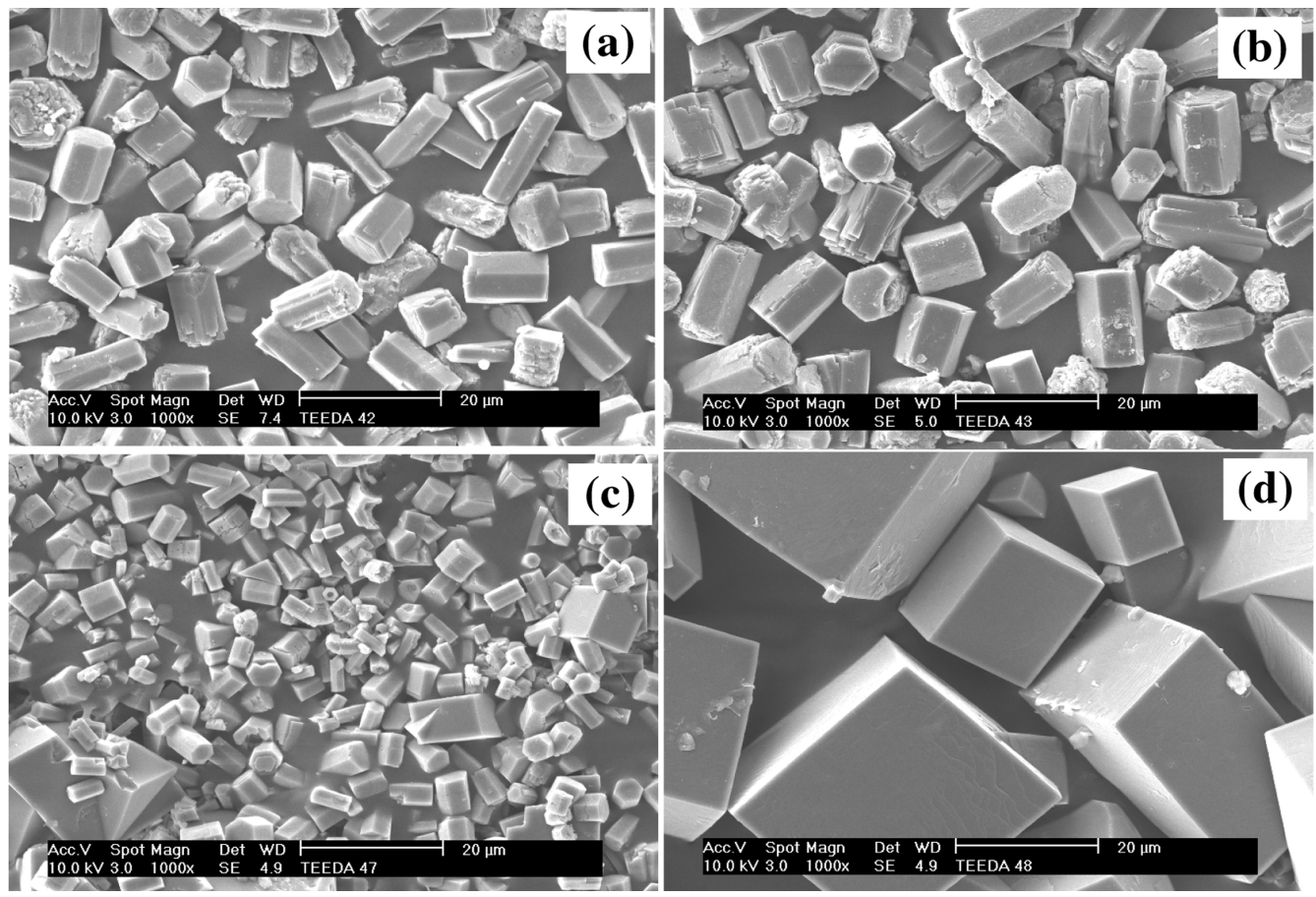

Figure 2. SEM images of SAPO molecular sieves synthesized from same alkaline gel containing TEEDA with microwave and conventional electric heating ((a): microwave heating for $0.5 \mathrm{~h}$, sample no. A of Table 1; (b): microwave heating for $2 \mathrm{~h}$, sample no. C of Table 1; (c): conventional electric heating for $12 \mathrm{~h}$, sample no. D of Table 1 ; (d) conventional electric heating for $48 \mathrm{~h}$, sample no. D of Table 1). 

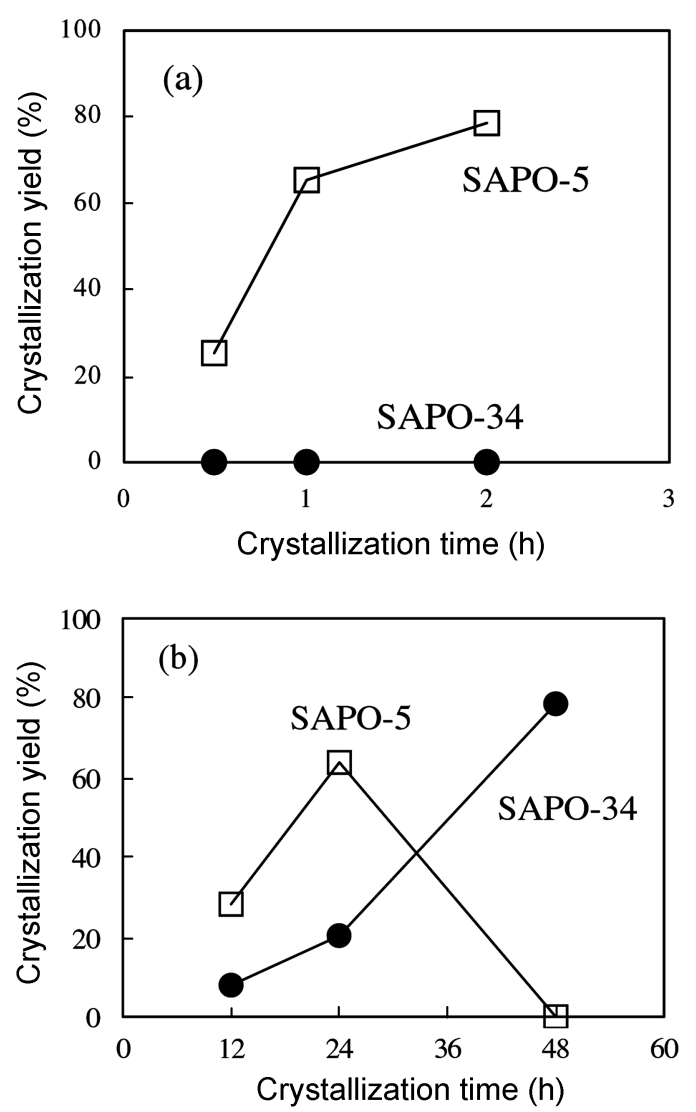

Figure 3. Competitive formation of SAPO-5 and SAPO-34 with (a) microwave heating and (b) conventional electric heating. Reactant composition was $\mathrm{Al}_{2} \mathrm{O}_{3}: 1.0 \mathrm{P}_{2} \mathrm{O}_{5}: 0.33 \mathrm{SiO}_{2}: 3.0$ TEEDA : $50 \mathrm{H}_{2} \mathrm{O}(\mathrm{pH}=9.0)$, and the synthesis temperature was $200^{\circ} \mathrm{C}$.

electric heating.

Figure 4 shows the XRD patterns of SAPO molecular sieves synthesized from neutral gel $\left(\mathrm{Al}_{2} \mathrm{O}_{3}: 1.0 \mathrm{P}_{2} \mathrm{O}_{5}\right.$ : $0.33 \mathrm{SiO}_{2}: 2.0$ TEEDA : $\left.100 \mathrm{H}_{2} \mathrm{O} ; \quad \mathrm{pH}=7.6\right)$ at $190{ }^{\circ} \mathrm{C}$. Similar to the synthesis of SAPO molecular sieves from an alkaline gel, the SAPO-5 and SAPO-34 are the major products of the crystallization of neutral gel with microwave and conventional electric heating, respectively.

\section{Discussion}

The microwave heating technique has many advantages in the hydrothermal synthesis of inorganic materials. For example, microwave technique can be utilized in the synthesis of relatively unstable molecular sieves such as Y, SAPO-5, VAPO-5 and CoAPO-34 because of the fast crystallization of the technique.

In this study, SAPO-5 and SAPO-34 are obtained from the crystallization of an alkaline gel using microwave and conventional electric heating, respectively (Table 1, Figs. 1, 2 ). This phase selectivity is also observed in wide reaction conditions including neutral (Fig. 4) or acidic gel ${ }^{13}$ using TEEDA as a template. Similar to the previous results ${ }^{23}$ the SAPO-5 synthesized by microwave heating should have similar physicochemical properties to the one synthesized by

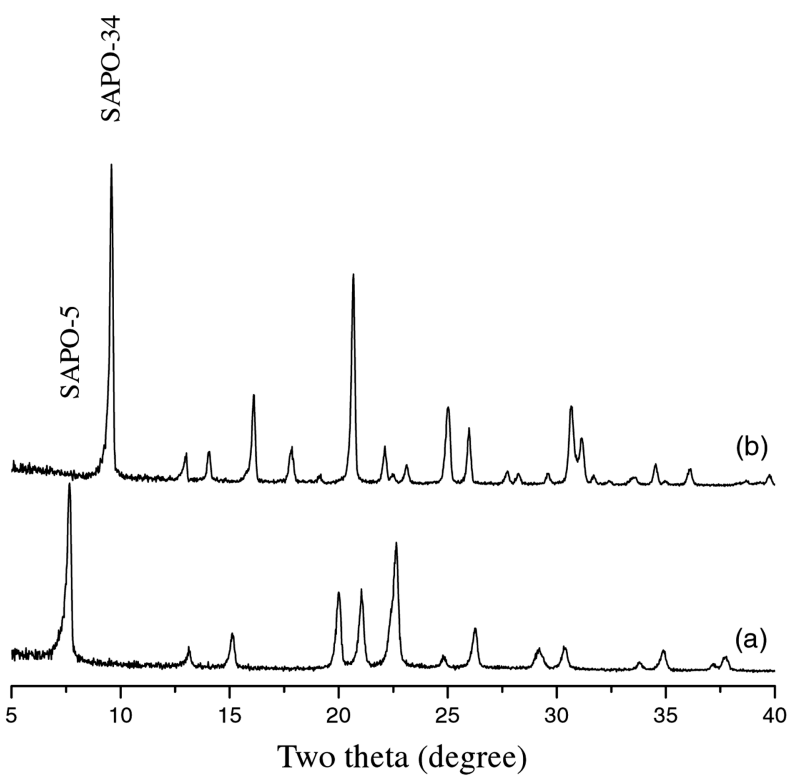

Figure 4. XRD patterns of SAPO molecular sieves synthesized from same neutral gel containing TEEDA with microwave and conventional electric heating at $190^{\circ} \mathrm{C}$. Reactant composition was $\mathrm{Al}_{2} \mathrm{O}_{3}: 1.0 \mathrm{P}_{2} \mathrm{O}_{5}: 0.33 \mathrm{SiO}_{2}:$.0TEEDA : $100 \mathrm{H}_{2} \mathrm{O} \quad(\mathrm{pH}=7.6) \quad((\mathrm{a}):$ microwave heating for $2 \mathrm{~h}$; (b): conventional electric heating for $84 \mathrm{~h})$.

conventional electric heating considering the similar BET surface area, morphology and XRD patterns.

As reported by Concepción et al. ${ }^{24}$ and Inoue et al. ${ }^{25}$ AFI (MgAPO-5 and SAPO-5) transforms into CHA (MgAPO-34 and SAPO-34) with increasing reaction time. This phase transformation was explained by the increased solubility of $\mathrm{AFI}^{24}$ and small crystallite size of $\mathrm{AFI},{ }^{25}$ and may indicate that $\mathrm{CHA}$ is more stable than AFI at the reaction condition. We also reported the phase transformation of SAPO-5 and VAPO-5 into SAPO-34 and VAPO-34, respectively, with the increase of crystallization time. ${ }^{13,14}$ However, CoAPO-34 transforms into CoAPO-5 with the reaction time ${ }^{14}$ to show the importance of the heteroatoms (incorporated in the molecular sieves) to the relative stability of the AFI and CHA structures. In this study, the SAPO-5 is gradually transformed into SAPO-34 with the increase of the crystallization time because of the relative stability of the phases as shown in Figure 3(b). Considering the previous results, ${ }^{13,14}$ the SAPO-34 probably will co-exist with SAPO-5 if the crystallization time increases further in the microwave heating. Therefore, as suggested in previous works, ${ }^{13,14}$ microwave technique can be utilized in the hydrothermal synthesis of relatively unstable structure because of the fast crystallization of the technique.

The SAPO-5 and SAPO-34 are typical AlPO-type molecular sieves that can be readily synthesized using various amines. In this study it has been found that TEEDA can be utilized for the synthesis of not only SAPO- $34^{20}$ but also SAPO-5 both in alkaline and neutral condition. Moreover, the synthesis of SAPO-5 by using microwave heating in a substantially reduced synthesis time in alkaline and neutral conditions is also confirmed. 


\section{Conclusions}

Following conclusions can be drawn from this study; - TEEDA can be used as a template in the synthesis of SAPO-5 and SAPO-34 in alkaline or neutral condition.

- The SAPO-5 and SAPO-34 can be selectively crystallized by the microwave heating and conventional electric heating, respectively, of the same alkaline gel containing TEEDA as a template. The SAPO-5 transforms into SAPO-34 with the increase of reaction time because of the relative stability of the SAPO-34 is higher than that of SAPO-5 in the reaction condition.

- The microwave heating technique can be suggested as a phase selective method for the preparation of relatively unstable materials because of fast crystallization of the technique.

Acknowledgements. This work was supported by the Korea Ministry of Science and Technology through International Program (KN-0428) and by the Korea Ministry of Commerce, Industry and Energy through Research Center for Nanocatalysts (KN-0427), one of the National Science Programs for Key Nanotechnology. The authors thank to beneficial contribution of Professor A. K. Cheetham, Dr. J.S. Hwang, Dr. Y. K. Hwang and Mr. J.-H. Lee.

\section{References}

1. Wilson, S. T.; Lok, B. M.; Messina, C. A.; Cannan, T. R.; Flanigen, E. M. J. Am. Chem. Soc. 1982, 104, 1146.

2. Davis, M. E. Nature 2002, 417, 813.

3. Arafat, A.; Jansen, J. C.; Ebaid, A. R.; Bekkum, H. van Zeolites 1990, 13, 162.

4. Cundy, C. S. Collect. Czech. Chem. Commum. 1998, 63, 1699.

5. (a) Park, M.; Komarneni, S. Micropor. Mesopor. Mater. 1998, 20, 39; (b) Kim, K. Y.; Ahn, W. S.; Park, D. W.; Oh, J. H.; Lee, C. M.; Tai, W. P. Bull. Kor. Chem. Soc. 2004, 25, 634.

6. Park, S.-E.; Chang, J.-S.; Hwang, Y. K.; Kim, D. S.; Jhung, S. H.; Hwang, J.-S. Catal. Survey Asia 2004, 8, 91.
7. Zhao, J. P.; Cundy, C.; Dwyer, J. Stud. Surf. Sci. Catal. 1997, 105, 181.

8. Xu, X.; Yang, W.; Liu, J.; Lin, L. Adv. Mater. 2000, 12, 195.

9. Kang, K.-K.; Park, C.-H.; Ahn, W.-S. Catal. Lett. 1999, 59, 45.

10. Jhung, S. H.; Chang, J.-S.; Hwang, Y. K.; Park, S.-E. J. Mater. Chem. 2004, 14, 280.

11. (a) Hwang, Y. K.; Chang, J.-S.; Kwon, Y.-U.; Park, S.-E. Micropor. Mesopor. Mater. 2004, 68, 21. (b) Hwang, Y. K.; Chang, J.-S.; Park, S.-E.; Kim, D. S.; Kwon, Y.-U.; Jhung, S. H.; Hwang, J.-S.; Park, M.-S. Angew. Chem. Intl. Ed. 2005, 44, 557.

12. (a) Jhung, S. H.; Chang, J.-S.; Park, S.-E.; Forster, P. M.; Férey, G.; Cheetham, A. K. Chem. Mater. 2004, 16, 1394; (b) Jhung, S. H.; Lee, J.-H.; Yoon, J. W.; Hwang, Y. K.; Hwang, J.-S.; Park, S.E.; Chang, J.-S. Mater. Lett. 2004, 58, 3161; (c) Jhung, S. H.; Chang, J.-S.; Yoon, J. W.; Grenéche, J.-M.; Férey, G.; Cheetham, A. K. Chem. Mater. 2004, 16, 5552; (d) Jhung, S. H.; Chang, J.-S.; Hwang, Y. K.; Grenéche, J.-M.; Férey, G.; Cheetham, A. K. J. Phys. Chem. B 2005, 109, 845.

13. Jhung, S. H.; Chang, J.-S.; Hwang, J. S.; Park, S.-E. Micropor. Mesopor. Mater. 2003, 64, 33.

14. Jhung, S. H.; Lee, J.-H.; Yoon, J. W.; Hwang, J.-S.; Park, S.-E.; Chang, J.-S. Micropor. Mesopor. Mater. 2005, 80, 147.

15. Meier, W. M.; Olson, D. H. Atlas of Zeolite Structure Types; Butterworths: London, 1987; p 18 and p 42.

16. Inui, T. Stud. Surf. Sci. Catal. 1997, 105, 1441.

17. Bora, B. V.; Marker, T. L.; Barger, P. T.; Nilsen, H. R.; Kvisle, S.; Fuglerud, T. Stud. Surf. Sci. Catal. 1997, 107, 87.

18. Jhung, S. H.; Hwang, Y. K.; Chang, J.-S.; Park, S.-E. Micropor. Mesopor. Mater. 2004, 67, 151.

19. Wilson, S. T. Stud. Surf. Sci. Catal. 2001, 137, 229.

20. Jhung, S. H. PhD Thesis, Korea Adv. Inst. Sci. Tech.; Seoul, Korea, 1990.

21. Treacy, M. M. J.; Higgins, J. B.; Ballmoos, R. von Collection of Simulated XRD Powder Patterns for Zeolites; Elsevier: New York, 1996; p 352.

22. Treacy, M. M. J.; Higgins, J. B.; Ballmoos, R. von Collection of Simulated XRD Powder Patterns for Zeolites; Elsevier: New York, 1996; p 409.

23. Jhung, S. H.; Chang, J.-S.; Kim, D. S.; Park, S.-E. Micropor. Mesopor. Mater. 2004, 71, 135.

24. Concepción, P.; Nieto, J. M. L.; Mifsud, A.; Pérez-Pariente, J. Zeolites 1996, 16, 56.

25. Inoue, M.; Dhupatemiya, P.; Phatanasri, S.; Inui, T. Micropor. Mesopor. Mater. 1999, 28, 19. 